\title{
A pulmonary rehabilitation program reduces levels of anxiety and depression in COPD patients
}

\author{
Athanasios Tselebis ${ }^{1 *}$, Dionisios Bratis ${ }^{1}$, Argiro Pachi ${ }^{1}$, Georgios Moussas ${ }^{1}$, loannis llias ${ }^{2}$, Maria Harikiopoulou ${ }^{3}$, \\ Elpida Theodorakopoulou ${ }^{3}$, Silvia Dumitru ${ }^{3}$, Epaminondas Kosmas ${ }^{3}$, Alexandros Vgontzas ${ }^{4}$, Nikolaos Siafakas ${ }^{5}$ \\ and Nikolaos Tzanakis ${ }^{5,6}$
}

\begin{abstract}
Background: The presence of anxiety and depressive symptoms in COPD patients has been acknowledged for many years. The preponderance of recent studies supports the utility of pulmonary rehabilitation programs to reduce the levels of depression and anxiety in these patients. The aim of this study is to investigate possible changes in levels of anxiety and depression among patients enrolled in a pulmonary rehabilitation program, along with the role of disease severity in these changes.

Methods: In 101 COPD patients, who attended a pulmonary rehabilitation program, levels of trait anxiety (STAl) and depressive symptoms (BDI) were assessed th the beginning and at the end of the program. Age, sex, level of education in years and stage of disease severity were recorded.

Results: Our study included 80 male and 21 female patients. Mean age and mean education level were $64.1 \pm 8.1$ and $11.3 \pm 4.1$ years, respectively. Regarding COPD staging, 11 patients suffered from mild, 16 from moderate, 47 from severe and 27 from very severe COPD. Significant decreases in anxiety (from 39.7 to 34.0, $p<0.001$ ) and depression rates (from 10.7 to $6.3, p<0.001$ ) were observed. A statistically significant reduction in anxiety and depression was revealed $(\mathrm{p}<0.05)$ at all stages of COPD.

Conclusion: Pulmonary rehabilitation programs should be offered to all COPD patients irrespective of disease severity, since they all lead to improvement in anxiety and depressive symptoms.
\end{abstract}

Keywords: Anxiety, Depression, COPD, Rehabilitation program

\section{Background}

Over the last decades, therapeutic evolution in healthcare, in conjunction with an increase in average life expectancy, resulted in a significant and gradual diminution in medical emergencies but simultaneously gave rise to chronic progressive and debilitating diseases.

Gradual reintegration of the chronically suffering patients in family, social and professional environment is nowadays a challenge for the therapeutic team. Social integration is continuously threatened by a constellation of factors concerning the nature of the disease and by the psychosocial parameters implicating the dynamic task of

\footnotetext{
* Correspondence: atselebis@yahoo.gr

${ }^{1}$ Psychiatric Department, "Sotiria" General Hospital of Chest Disease, Athens, Greece

Full list of author information is available at the end of the article
}

adjustment mechanisms that constitute the subjective experience of the illness.

It is well known that Chronic Obstructive Pulmonary Disease (COPD) is a disease with psychological comorbidities. Several studies have suggested that the prevalence of anxiety and depression among patients with COPD is substantially greater than lifetime rates in the general population and higher than in patients with other pulmonary diseases such as bronchial asthma and tuberculosis [1], or other chronic diseases such as chronic heart failure [2]. International prevalence rates of clinical depression in COPD patients rise above 30\% and sometimes above $50 \%$ [3], whereas corresponding rates in the background population is around 6-8\% [4]. Studies in Greece also report high prevalence rates of depression in COPD patients, often above 42\% [1]. Moreover, studies indicate rates of anxiety varying

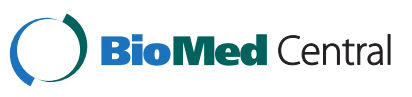


from $10 \%$ to $19 \%$ [3], which is higher than the prevalence rate of $15 \%$ mentioned in the general population [5]. Additionally, one out of two patients with COPD disease appears to suffer from general psychopathological symptoms [6].

Recent studies show a reduction in anxiety and depression symptoms among patients with COPD that are enrolled in pulmonary rehabilitation programs [7-9]; nevertheless some authors believe that further studies are needed [10]. Several studies have pointed out that the degree of psychological improvement brought about by the program depends on disease severity stage. These studies mostly deal with severe COPD (usually leaving out stage I disease) $[11,12]$.

The aim of this study is to investigate the change in anxiety and depressive symptoms among patients with COPD disease who attended a pulmonary rehabilitation program, along with the effect of disease severity on this change. Specifically, we assessed whether the rehabilitation program alters anxiety and depression in patients with COPD, and if this change depends on disease stage, severity and gender.

\section{Method}

\section{Sample}

The study lasted four years and involved all patients with COPD who attended a pulmonary rehabilitation program and met the criteria for inclusion in the study. All interested patients with COPD (for whom there was no contraindication such as angina pectoris, myocardial infarction, severe pulmonary hypertension, congestive heart failure, labile diabetes, inability to exercise due to orthopedic or other reasons, dementia or severe hypoxia caused by exercise and corrected by $\mathrm{O}_{2}$ administration) were admitted to this rehabilitation program [13]. The sample consisted of 101 COPD patients, 80 males and 21 females, who completed a three months program. Inclusion criteria were the following: age less than 80 years, without other chronic comorbid medical conditions (cardiovascular diseases, major psychiatric disorders, etc.) and absence of acute exacerbation of COPD during the last two months before starting the program. We excluded patients who did not meet the inclusion criteria $(\mathrm{n}=12)$ as well as those who did not complete the rehabilitation program $(n=43)$.

\section{Physical measures}

In order to determine COPD severity of our sample, a spirometric evaluation before and after bronchodilation (200 $\mu \mathrm{g}$ salbutamol) was performed. We followed the Global Initiative for Chronic Obstructive Lung Disease (GOLD) diagnostic criteria, which classifies COPD severity [in relation to forced expiratory volume in 1 second $\left(\mathrm{FEV}_{1}\right) /$ forced vital capacity $(\mathrm{FVC})$ ratio $\left(\mathrm{FEV}_{1} \%\right)$ - percentage of predicted] into four stages: stage I (mild COPD): $\mathrm{FEV}_{1}>80 \%$ predicted; stage II (moderate COPD): $\mathrm{FEV}_{1} 50 \%$ to $80 \%$ of predicted; stage III (severe $\mathrm{COPD}$ ): $\mathrm{FEV}_{1} 30 \%$ to $50 \%$ of predicted; and stage IV (very severe COPD): $\mathrm{FEV}_{1}<30 \%$ of predicted [14]. The spirometric evaluation of each patient was performed a few days before he/she started the rehabilitation program.

\section{Psychological measures}

Depression was assessed with the Beck Depression Inventory (BDI) [15], which is widely used, and has been standardized [16] and used in the Greek population previously [17]. The BDI includes 21 items graded from 0 to 3 . The inner coherence reliability is high and the retest reliability ranges from 0.48 to 0.86 for clinical groups and 0.60 to 0.90 for non-clinical population. Its validity in relation to an external criterion for depression, such as clinical diagnosis, is considered to be satisfactory. Anxiety was assessed with the Spielberger State-Trait Anxiety Inventory (SSTAI) [18], one of the well-known and broadly used anxiety rating scales. The inventory consists of 40 items, each one graded from 1 to 4 . The SSTAI differentiates anxiety to (a) anxiety caused by a specific condition (state subscale), and (b) anxiety as a more permanent characteristic of the personality (trait subscale). This second (trait) subscale was used in our study protocol. The SSTAI is considered as having a high inner coherence reliability and validity compared to clinical diagnosis. Also it has been standardized [19] and widely used in studies in the Greek population previously [20]. Participants replied to the questionnaires in two phases, at baseline and at discharge from the pulmonary rehabilitation program.

\section{Pulmonary rehabilitation program}

Patients of our study followed a pulmonary rehabilitation program for a period of three months, with three sessions per week, each lasting 50 minutes. The program included respiratory physiotherapy, respiratory muscle training, aerobic exercise on a bicycle ergometer and on a treadmill and strengthening of muscle groups. The exercise was performed with oxygen supplementation while simultaneously recording heart rate and hemoglobin saturation. The minimum and maximum number of sessions per patient was 34 and 39, respectively, with an average of 37 per patient.

\section{Statistical analysis}

The statistical program used was SPSS 16. The statistical analysis was performed using $x^{2}$ test, paired $t$-test, ANOVA, sample $t$-test, Pearson correlation and stepwise multiple regression. For regression models, an empirical 
approach was used after correlation analysis. Statistical significance was set at $\mathrm{p}<0.05$.

The hospital ethics committee approved the study and all participants provided written informed consent. No financial support was necessary.

\section{Results}

\section{Sample characteristics}

The demographic characteristics of our patients and their spirometric values are summarized in Table 1. There were no differences between genders regarding age, years of education and $\mathrm{FEV}_{1}$ percentage of predicted $(t$-test $\mathrm{p}>0.05)$. With regard to the severity of COPD according to GOLD classification, the number of patients with severe COPD disease (47 patients, $46.5 \%$ of the total sample) was significantly higher than that of other subgroups $\left(x^{2} \mathrm{p}<0.01\right.$, Table 1$)$.

\section{Changes in anxiety and depression}

Mean depression and anxiety scores were significantly lower at discharge compared to baseline for all our patients (paired $t$-test $\mathrm{p}<0.05$, Table 2). Same findings were revealed for all subgroups (according to staging of COPD disease) of patients and no statistical difference was identified when checking for mean individual changes in depression and anxiety scores among all different disease severity subgroups (ANOVA $\mathrm{p}>0.05$ ).

Mean BDI score, at baseline, for the total of our sample was 10.7, which is significantly (sample $t$-test $\mathrm{p}<0.05$ ) higher than the corresponding mean score (5.86) [16] in the general population. At discharge from the program, mean BDI score was 6.33, not statistically different from the corresponding mean score in the general population (sample $t$-test $\mathrm{p}>0.05$ ). The rate of patients who had depressive symptoms $($ BDI $>9)$ [16] at baseline was $47.5 \%$ (48 patients, Table 3 ) whereas at discharge it became $14.9 \%$ (15 patients, Table 3), which was a statistically significant reduction $\left(x^{2} \mathrm{p}<0.05\right)$.

\section{Changes in anxiety and depression per gender}

Regarding anxiety scores our observations indicated that mean scores at baseline were higher than the corresponding scores in the general population. Specifically, female patients of our sample had a mean STAI score of 42.62 (versus 37.47 [19] in the general female population, sample $t$-test $\mathrm{p}<0.01$ ), while men had an average of 38.87 (versus 34.54 [19] in the general male population, sample $t$-test $p<0.01)$. At discharge our study indicated reduced mean STAI scores for both female (36.29) and male patients (33.4). These scores were not statistically different from the corresponding mean scores in the general population (sample $t$-test $\mathrm{p}>0.05$ ). The rate of female patients who had clinically significant anxiety symptoms $(\mathrm{STAI}>45)$ at baseline was $47.6 \%$ and was reduced to $19 \%$ at discharge $\left(x^{2} \mathrm{p}<0.05\right)$. Regarding male patients of our sample, $25 \%$ of them had clinically significant anxiety symptoms $(\mathrm{STAI}>43)$ at baseline and the percentage was reduced to $12.5 \%$ at discharge $\left(x^{2} \mathrm{p}<0.05\right)$.

\section{Correlations}

A significant positive correlation was observed between anxiety and depression scores both at baseline and at discharge from the program (Pearson correlation $\mathrm{p}<0.01$, Table 4).

A significant positive correlation was also observed between first and last measuring for both anxiety and depression (Pearson correlation $\mathrm{p}<0.01$, Table 3 ), but no correlation was found between $\mathrm{FEV}_{1} \%$ of predicted and anxiety - depression scores (Pearson correlation $\mathrm{p}>0.05$, Table 4).

Table 1 Demographics and baseline characteristics

\begin{tabular}{|c|c|c|c|c|c|c|}
\hline & & Age & $\begin{array}{c}\text { Education level } \\
\text { (years) }\end{array}$ & $\begin{array}{c}\text { FEV }_{1} \\
\text { (\% of predicted) }\end{array}$ & $\begin{array}{l}\text { Depression } \\
\text { (BDI) }\end{array}$ & $\begin{array}{c}\text { Anxiety } \\
\text { (STAI) }\end{array}$ \\
\hline \multirow[t]{3}{*}{ Male } & Mean & 64.56 & 10.90 & 41.98 & 10.39 & 38.88 \\
\hline & N & 80 & 80 & 80 & 80 & 80 \\
\hline & SD & 8.06 & 4.09 & 21.25 & 6.62 & 9.68 \\
\hline \multirow[t]{3}{*}{ Female } & Mean & 62.57 & 12.67 & 49.53 & 11.90 & 42.62 \\
\hline & $N$ & 21 & 21 & 21 & 21 & 21 \\
\hline & SD & 8.38 & 3.75 & 22.13 & 5.72 & 8.27 \\
\hline \multirow[t]{3}{*}{ Total } & Mean & 64.15 & 11.27 & 43.51 & 10.7 & 39.65 \\
\hline & $\mathrm{N}$ & 101 & 101 & 101 & 101 & 101 \\
\hline & SD & 8.13 & 4.07 & 21.53 & 6.45 & 9.49 \\
\hline \multicolumn{7}{|c|}{ Severity according to Global Initiative for Chronic Obstructive Lung Disease (GOLD) diagnostic criteria: } \\
\hline \multicolumn{7}{|c|}{ mild/moderate/severe/very severe: 11 (10.9\%)/16 (15.8\%)/47 (46.5\%)/27 (26.7\%). } \\
\hline
\end{tabular}


Table 2 Means (SD) and differences in BDI and STAI at baseline and after PRP in COPD severity subgroups

\begin{tabular}{|c|c|c|c|c|c|c|c|}
\hline \multirow{2}{*}{$\begin{array}{l}\text { COPD Severity } \\
\text { (as per GOLD) }\end{array}$} & & \multicolumn{2}{|c|}{ Time 1} & \multicolumn{2}{|c|}{ Time 2} & \multicolumn{2}{|c|}{ Difference } \\
\hline & & Depression & Anxiety & Depression & Anxiety & Depression & Anxiety \\
\hline & & & & & & & \\
\hline mild & Mean & 12.27 & 43.18 & 8.36 & 39.27 & $-3.91^{*}$ & $-3.91^{*}$ \\
\hline$N=11$ & SD & 5.55 & 8.15 & 7.21 & 9.88 & 5.24 & 5.86 \\
\hline moderate & Mean & 8.44 & 38.75 & 4.06 & 30.62 & $-4.37^{*}$ & $-8.12^{* *}$ \\
\hline$N=16$ & SD & 5.66 & 8.34 & 2.67 & 7.59 & 6.91 & 8,20 \\
\hline severe & Mean & 11.43 & 39.62 & 6.85 & 33.96 & $-4.57^{* *}$ & $-5.66^{* *}$ \\
\hline$N=47$ & SD & 7.58 & 10.59 & 6.04 & 9.34 & 5.73 & 8.08 \\
\hline very severe & Mean & 10.15 & 38.81 & 5.93 & 33.93 & $-4.22^{* *}$ & $-4.89^{* *}$ \\
\hline$N=27$ & SD & 4.75 & 8.71 & 5.48 & 8.39 & 4.77 & 5.65 \\
\hline Total & Mean & 10.70 & 39.65 & 6.33 & 34.00 & $-4.38^{* *}$ & $-5.65^{* *}$ \\
\hline$N=101$ & SD & 6.45 & 9.49 & 5.69 & 9.04 & 5.56 & 7.30 \\
\hline
\end{tabular}

* Paired t-test $p<0.05$.

**Paired t-test $\mathrm{p}<0.01$

$B D I$ Beck depression inventory, STAI Spielberger trait anxiety inventory.

More in detail, we implemented stepwise multiple regression analysis using variation in depression as the dependent variable and controlling for gender, age, $\mathrm{FEV}_{1} \%$, years of education and variation in anxiety (independent variables). Gender, age, years of education and $\mathrm{FEV}_{1} \%$ were not involved in the variance of the dependent variable whereas variation in anxiety interpreted $34.3 \%$ of variation in depression (f $1.97=$ 50.62, $\mathrm{p}<0.01)$. Considering anxiety variation as the dependent variable and gender, age, years of education, $\mathrm{FEV}_{1} \%$ as independent variables the results were not different, since variation in anxiety scores was independent of gender, age and $\mathrm{FEV}_{1} \%$, whereas variation in depression interpreted $34.3 \%$ of variation in anxiety (f $1.97=$ 50.62, p <0. 01).

\section{Discussion}

Summarizing the results of this study, we have shown that a rehabilitation program can reduce the high levels of anxiety and depression in patients with COPD. Improvement occurs for patients in all disease stages (with no statistically significant differences among them), irrespective of gender. This improvement is not dependent on disease stage, gender, age or years of education. Spirometry showed no correlation with either anxiety or depression in the course of the program and anxiety and depression were not correlated with the severity of COPD".

Despite the high prevalence and harmful effects attributed to the comorbidity of anxiety and depression in COPD, only a limited number of studies have addressed their management $[21,22]$.

Drug treatment encounters serious problems. Benzodiazepines may cause respiratory depression and should be avoided [23]. In addition, beta-blockers are contraindicated in these patients, despite their anxiolytic action, because of the potential risk of bronchoconstriction [24]. Atypical antipsychotics in very small doses can alleviate anxiety symptoms in these patients, but they should be used cautiously because of possible neurological and cardiovascular side effects [25]. In other studies SSRIs have been used (first-line drugs for the management of depression) [26-30]. Sertraline [28,29], fluoxetine [26,31] citalopram [32] and paroxetine [30] may improve quality

Table 3 Severity of COPD and depressive symptoms severity

\begin{tabular}{|c|c|c|c|c|c|c|c|c|c|c|}
\hline & & \multicolumn{8}{|c|}{ Depressive symptoms severity } & \multirow[t]{3}{*}{ Total } \\
\hline & & \multicolumn{2}{|c|}{ BDI: $0-9$} & \multicolumn{2}{|c|}{ BDI:10-18 } & \multicolumn{2}{|c|}{ BDI:19-29 } & \multicolumn{2}{|c|}{ BDI $>29$} & \\
\hline & & time one & time two & time one & time two & time one & time two & time one & time two & \\
\hline \multirow[t]{4}{*}{ COPD Severity (GOLD criteria) } & Mild & 3 & 9 & 7 & 1 & 1 & 1 & 0 & 0 & 11 \\
\hline & Moderate & 11 & 16 & 4 & 0 & 1 & 0 & 0 & 0 & 16 \\
\hline & Severe & 24 & 36 & 17 & 9 & 5 & 1 & 1 & 1 & 47 \\
\hline & Very severe & 15 & 25 & 10 & 1 & 2 & 1 & 0 & 0 & 27 \\
\hline Total & & 53 & 86 & 38 & 11 & 9 & 3 & 1 & 1 & 101 \\
\hline
\end{tabular}


Table 4 Correlations

\begin{tabular}{|c|c|c|c|c|c|c|c|}
\hline $\mathrm{N}=101$ & & AGE & Education (years) & $\mathrm{FEV}_{1} \%$ & BDI 1 & BDI 2 & STAI 1 \\
\hline \multirow[t]{2}{*}{ Education level (in years) } & Pearsons' $r$ & -.063 & & & & & \\
\hline & Sig. (2-tailed) & .532 & & & & & \\
\hline \multirow[t]{2}{*}{$\mathrm{FEV}_{1} \%$} & Pearsons' $r$ & .095 & .014 & & & & \\
\hline & Sig. (2-tailed) & .349 & .893 & & & & \\
\hline \multirow[t]{2}{*}{ Depression (BDI 1) Time 1} & Pearsons' $r$ & -.076 & -.056 & .010 & & & \\
\hline & Sig. (2-tailed) & .447 & .575 & .923 & & & \\
\hline \multirow[t]{2}{*}{ Depression (BDI 2) Time 2} & Pearsons' $r$ & -.091 & .097 & .053 & $.586^{* *}$ & & \\
\hline & Sig. (2-tailed) & .365 & .337 & .601 & .000 & & \\
\hline \multirow[t]{2}{*}{ Anxiety (STAI 1) Time 1} & Pearsons' $r$ & $-.223^{*}$ & -.056 & .034 & $.726^{* *}$ & $.408^{* *}$ & \\
\hline & Sig. (2-tailed) & .025 & .575 & .741 & .000 & .000 & \\
\hline \multirow[t]{2}{*}{ Anxiety (STAI 2) Time 2} & Pearsons' $r$ & -.194 & .131 & .041 & $.610^{* *}$ & $.717^{* *}$ & $.691^{* *}$ \\
\hline & Sig. (2-tailed) & .052 & .190 & .688 & .000 & .000 & .000 \\
\hline
\end{tabular}

* Correlation is significant at the 0.05 level (2-tailed).

** Correlation is significant at the 0.01 level (2-tailed).

$B D I$ Beck depression inventory, STAI, Spielberger trait anxiety inventory.

of life, however it is noted that patients with COPD and psychiatric comorbidity are reluctant to take additional medications [26,33].

Both individual and group therapy are useful for the treatment of patients with COPD [34]. The comparison of individual and group intervention usually favors the latter [35-41]. Group therapy is a financially attractive treatment approach that requires few therapists to treat more patients. Furthermore it seems that group therapy offers valuable treatment opportunities, which may be due to recognition of shared experiences and emotions among its members in a situation resembling the real world more accurately [39].

It is very likely that improvement of psychological symptoms in rehabilitation programs is associated with both psychological, and biological parameters (which are closely coupled with the effects of exercise and respiratory physiotherapy).

Biological mechanisms associated with exercise activity, including changes in central monoamine function [36-40], enhanced hypothalamic- pituitary- adrenal axis regulation, increased release of endogenous opioids [42-49] and reduced systemic inflammation [49,50], may affect depression and anxiety among patients undergoing PR. In addition, behavioral mechanisms [51-56] associated with exercise activity as active distraction from worrying thought patterns (rumination), increase in selfefficacy by providing patients with a meaningful mastery experience, provision of daily pleasant events and regular social contact and support, operate synergistically to produce reductions of symptoms.

The fact that patients participate in a pulmonary rehabilitation program, which, with the necessary modifications, works in a way that refers to the functioning of groups formed by people sharing common characteristics [39], acts therapeutically. Moreover, it is well knownthat the sense of belonging to a group is often beneficial, as it provides the opportunity for participants to trigger interactions and through this process to identify elements of personal experience among others, and to process them in a healthier way [57].

The results of this study are consistent with reports of strong evidence of psychological/psychiatric benefits of pulmonary rehabilitation [58-61], (such as improved mood and anxiety) in patients with COPD $[62,63]$. This study is in accordance with previous findings indicating that patients with less favorable psychological conditions may also benefit from a rehabilitation program [64].

An additional finding is that the effectiveness of a pulmonary rehabilitation program in reducing stress and depressive symptoms experienced by patients with COPD, is undeniable, regardless of disease stage, patients' gender, age or education level.

Furthermore, this study is in agreement with findings of other related works $[29,30]$ that reported anxiety and depression as being the major comorbidity problem in patients with COPD. However, the prevalence of comorbidity seems to vary widely among different researchers [25,65-67]. The acceptance of common assessment tools for stress and depression in patients with COPD could mitigate the problem.

Finally, the positive correlation between anxiety and depression is a common finding in both the general population $[5,20]$ and in patients with COPD $[1,6,68]$.

The fact that the predicted $\mathrm{FEV}_{1} \%$ and severity of COPD showed no correlation with anxiety or depression has been observed in other studies [6,68]. These observations are consistent with the hypothesis that the 
predicted $\mathrm{FEV}_{1} \%$ does not reflect all aspects of the disease [69]. It is likely that patients interpret disease seriousness subjectively, which contributes to the development of the levels of anxiety and depressive symptoms.

\section{Limitations of the study}

The purpose of this study was to assess whether a brief three month rehabilitation program can improve levels of anxiety and depression in patients with COPD without being able to answerbut only to speculate on the reasons for this improvement. Subsequent studies should focus on exploring the causes of the improvement.

This was a short-term before-and-after design study (which is most useful in delineating immediate effects of short-term programs). Although it might be more useful in COPD patients to assess longer-term repercussions of the rehabilitation program this was beyond the scope of this study (after all over a longer time period of time conditions may change and obscure any intervention's effects by threatening the study's internal validity). The fact that the number of men was unequal to that of women may actually underestimate baseline anxiety and depression scores, since women tend to have higher levels of both, but such a choice would have eliminated the representativeness of the sample (women with COPD, despite a steady increase in number, still remain fewer than men). An important problem in the study is that a substantial number of patients have chosen to discontinue the rehabilitation program and a subsequent study should examine whether psychological factors are involved in patients attrition. Understanding the problem should not aim at excluding patients with COPD from rehabilitation programs, but to create individualized interventions both before and during rehabilitation.

\section{Conclusion}

Our study supports that pulmonary rehabilitation programs should be offered to all COPD patients regardless of disease severity, since they all get improvements in anxiety and depressive symptoms. Further research would be useful to confirm these findings and to focus on the possibilities of intervention and rehabilitation in patients with mild COPD.

\section{Competing interests}

The authors declare that they have no competing interests.

\section{Authors' contributions}

AT conceived the experiment, designed the study, performed the psychological measures, collected data, carried out the statistical analysis and drafted the paper; DB performed the psychological measures, carried out the statistical analysis and drafted the paper; AP and GM helped draft the paper; II carried out the statistical analysis and helped draft the paper; EK performed the physical measures and helped draft the paper; $\mathrm{MH}, \mathrm{ET}$ and SD performed the physical measures; NS and AV supervised the study; NT carried out the statistical analysis, helped draft the paper and supervised the study. All authors read and approved the final manuscript.

\section{Author details}

'Psychiatric Department, "Sotiria" General Hospital of Chest Disease, Athens, Greece. ${ }^{2}$ Endocrinology Department, "Elena Venizelou" Hospital, Athens, Greece. ${ }^{3}$ Pulmonary Rehabilitation Centre, "Sotiria" General Hospital of Chest Diseases, Athens, Greece. ${ }^{4}$ Psychiatric Department, University of Crete, Medical School, Heraklion, Greece. ${ }^{5}$ Department of Thoracic Medicine, University of Crete, Medical School, Heraklion, Greece. ${ }^{6}$ Department of Social Medicine, Laboratory of Epidemiology, University of Crete, Medical School, Heraklion, Greece.

Received: 7 January 2013 Accepted: 23 May 2013

Published: 22 June 2013

\section{References}

1. Moussas G, Tselebis A, Karkanias A, Stamouli D, llias I, Bratis D, Vassila-Demi $K:$ A comparative study of anxiety and depression in patients with bronchial asthma, chronic obstructive pulmonary disease and tuberculosis in a general hospital of chest diseases. Ann Gen Psychiatry 2008, 7:7.

2. Yohannes AM, Willgoss TG, Baldwin RC, Connolly MJ: Depression and anxiety in chronic heart failure and chronic obstructive pulmonary disease: prevalence, relevance, clinical implications and management principles. Int I Geriatr Psychiatry 2010, 25:1209-1221.

3. Maurer J, Rebbapragada V, Borson S, Goldstein R, Kunik ME, Yohannes AM, Hanania NA, ACCP Workshop Panel on Anxiety and Depression in COPD: Anxiety and depression in COPD: current understanding, unanswered questions, and research needs. Chest 2008, 134 suppl:43S-56S.

4. Wells KB, Golding J, Burnan MA: Psychiatric disorder in a sample of the general population with and without chronic medical conditions. Am J Psychiatry 1998, 145:976-979.

5. Tselebis A, Gournas G, Tzitzanidou G, Panagiotou A, llias I: Anxiety and depression in Greek nursing and medical personnel. Psychol Rep 2006, 99:93-96.

6. Tselebis A, Bratis D, Kosmas E, Harikiopoulou M, Theodorakopoulou E, Dumitru S, Moussas G, Karkanias A, llias I, Siafakas N, Vgontzas A, Tzanakis N: Psychological symptom patterns and vital exhaustion in outpatients with chronic obstructive pulmonary disease. Ann Gen Psychiatry 2011, 10:32.

7. Emery CF, Schein RL, Hauck ER, Maclntyre NR: Psychosocial and cognitive outcomes of a randomized trial of exercise among patients with chronic obstructive pulmonary disease. Health Psychol 1998, 17:232-240.

8. Griffiths TL, Burr ML, Campbell IA, Lewis-Jenkins V, Mullins J, Shiels K, TurnerLawlor PJ, Payne N, Newcombe RG, Ionescu AA, Thomas J, Tunbridge J: Results at 1 year of outpatient multidisciplinary pulmonary rehabilitation: a randomised controlled trial. Lancet 2000, 355:362-368.

9. Guell R, Resqueti V, Sangenis M, Morante F, Martorell B, Casan P, Guyatt GH: Impact of pulmonary rehabilitation on psychosocial morbidity in patients with severe COPD. Chest 2006, 129:899-904.

10. Ries AL, Bauldoff GS, Carlin BW, Casaburi R, Emery CF, Mahler DA, Make B, Rochester CL, Zuwallack R, Herrerias C: Pulmonary Rehabilitation: Joint ACCP/AACVPR Evidence-Based Clinical Practice Guidelines. Chest 2007, 131 ( 5 Suppl):4S-42S

11. Güell R, Resqueti V, Sangenis M, Morante F, Martorell B, Casan P, Guyatt GH: Impact of pulmonary rehabilitation on psychosocial morbidity in patients with severe COPD. Chest 2006, 129:899-904.

12. Withers NJ, Rudkin ST, White RJ: Anxiety and depression in severe chronic obstructive pulmonary disease: the effects ofpulmonary rehabilitation. J Cardiopulm Rehabil 1999, 19:362-365.

13. Hui KP, Hewitt AB: A simple pulmonary rehabilitation program improves health outcomes and reduces hospital utilization in patients with COPD. Chest 2003, 124:94-97.

14. Global Initiative for Chronic Obstructive Lung Disease: Global Strategy for the Diagnosis, Management, and Prevention of Chronic Obstructive Pulmonary Disease (GOLD). . http://www.goldcopd.org.

15. Beck AT, Steer RA: Manual for the Revised Beck Depression Inventory. San Antonio, TX: Psychological Corporation; 1987.

16. Donias S, Demertzis I: Validation of the Beck depression inventory. In Proceedings of the 10th Hellenic Congress of Neurology and Psychiatry: 1983. 
Edited by Varfis G. Thessaloniki, Greece: University Studio Press; 1983:486-492

17. Tselebis A, Moulou A, llias I: Burnout versus depression and sense of coherence: A study in Greek nursing staff. Nurs Health Sci 2001, 3:69-71.

18. Spielberger GD, Gorush RL, Lusshene RE: The State-Trait Anxiety Inventory. Palo Alto, CA: Consulting Psychologists Press; 1970.

19. Liakos A, Giannitsi S: The validity of the Greek modification of the Spielberger anxiety scale. Encephalos 1984, 21:71-76.

20. Tselebis A, Papaleftheris E, Balis E, Theotoka I, Ilias I: Smoking related to anxiety and depression in Greek medical staff. Psychol Rep 2003, 92:529-532

21. Di Marco F, Verga M, Reggente M, Maria Casanova F, Santus P, Blasi F, Allegra L, Centanni S: Anxiety and depression in COPD patients: the roles of gender and disease severity. Respir Med 2006, 100:1767-1774.

22. Voekel M, Voelkel NF, MacNee W: Chronic Obstructive Lung Diseases 2. Psychosocial aspects of Chronic Obstructive Pulmonary Disease. BC Decker Inc: City; 2008.

23. Man GCW, Hsu K, Spoule BJ: Effect of alprazolam on exercise and dyspnea in patients with chronic obstructive pulmonary disease. Chest 1986, 90:832-836.

24. Cantor $L$, Jacobson R: COPD: How to manage comorbid depression and anxiety. J Fam Pract 2003, 2:11.

25. Mikkelsen RL, Middelboe T, Pisinger C, Stage KB: Anxiety and depression in patients with chronic obstructive pulmonary disease (COPD). A review. Nord J Psychiatry 2004, 58:65-70.

26. Yohannes AM, Connolly MJ, Baldwin RC: A feasibility study of antidepressant drug therapy in depressed elderly patients with chronic obstructive pulmonary disease. Int J Geriatr Psychiatry 2001, 16:451-454.

27. Eiser N, Harte R, Spiros K: Effect of treating depression on quality-of-life and exercise tolerance in severe COPD. COPD 2005, 2:233-241.

28. Papp LA, Weiss JR, Greenberg HE, Rifkin A, Scharf SM, Gorman JM, Klein DF Sertraline for chronic obstructive pulmonary disease and comorbid anxiety and mood disorders. Am J Psychiatry 1995, 152:1531.

29. Smoller JW, Pollack MH, Systrom D, Kradin RL: Sertraline effects on dyspnea in patients with obstructive airways disease. Psychosomatics 1998, 39:24-29.

30. Lacasse $Y$, Beaudoin $L$, Rousseau L, Maltais F: Randomized trial of paroxetine in end-stage COPD. Monaldi Arch Chest Dis 2004, 61:140-147.

31. Evans M, Hammond M, Wilson K, Lye M, Copeland J: Placebo controlled treatment trial of depression in elderly physically ill patients. Int J Geriatr Psychiatry 1997, 12:817-824.

32. Silvertooth EJ, Doraiswamy PM, Clary GL, Babyak MA, Wilkerson N, Hellegars C, Palmer SM: Citalopram and quality of life in lung transplant recipients. Psychosomatics 2004, 45:271-272

33. Yohannes AM, Connolly MJ: Do antidepressants work in patients with chronic obstructive pulmonary disease with comorbid depression? Expert Rev Respir Med 2011, 5(6):727-729.

34. Post $L$, Collins C: The poorly coping COPD patient: a psychotherapeutic perspective. Int J Psychiatry Med 1981-1982, 11(2):173-182.

35. Kunik ME, Braun U, Stanley MA, Wristers K, Molinari V, Stoebner D, Orengo CA: One session cognitive behavioural therapy for elderly patients with chronic obstructive pulmonary disease. Psychol Med 2001, 31:717-723.

36. Eiser N, West C, Evans S, Jeffers A, Quirk F: Effects of psychotherapy in moderately severe COPD: a pilot study. Eur Respir J 1997, 10:1581-1584.

37. de Godoy DV, de Godoy RF: A randomized controlled trial of the effect of psychotherapy on anxiety and depression in chronic obstructive pulmonary disease. Arch Phys Med Rehabil 2003, 84:1154-1157.

38. Kunik ME, Veazey C, Cully JA, Souchek J, Graham DP, Hopko D, Carter R, Sharafkhaneh A, Goepfert EJ, Wray N, Stanley MA: COPD education and cognitive behavioral therapy group treatment for clinically significant symptoms of depression and anxiety in COPD patients; a randomized controlled trial. Psychol Med 2008, 38:385-396.

39. Brook D: Exploring Group Therapies. Psychiatric Times 2003. http://www psychiatrictimes.com/articles/exploring-group-therapies.

40. Dishman RK: Brain monoamines, exercise, and behavioral stress: animal models. Med Sci Sports Exerc 1997, 29(1):63-74.

41. Ransford CP: A role for amines in the antidepressant effect of exercise: a review. Med Sci Sports Exerc 1982, 14(1):1-10.

42. Dunn AL, Reigle TG, Youngstedt SD, Armstrong RB, Dishman RK: Brain norepinephrine and metabolites after treadmill training and wheel running in rats. Med Sci Sports Exerc 1996, 28(2):204-209.
43. Jacobs BL: Serotonin, motor activity and depression-related disorders. Am Sci 1994, 82:456-463.

44. Chaouloff F: Effects of acute exercise on central serotonergic systems. Med Sci Sports Exerc 1997, 29(1):58-62.

45. Raglin JS, Morgan WP: Influence of exercise and quiet rest on state anxiety and blood pressure. Med Sci Sports Exerc 1981, 19(5):456-463.

46. Carr DB, Bullen BA, Skrinar GS, Arnold MA, Rosenblatt M, Beitins IZ, Martin $J B$, McArthur JW: Physical conditioning facilitates the exercise-induced secretion of beta-endorphin and beta-lipotropin in women. $N$ Engl J Med 1981, 305(10):560-563.

47. Farrell PA, Gates WK, Maksud MG, Morgan WP: Increases in plasma beta endorphin/beta-lipotropinimmunoreactivity after treadmillrunning in humans. J Appl Physiol 1982, 52(5):1245-1249.

48. Gambert SR, Hagen TC, Garthwaite TL: Exercise and the endogenous opioids. N Engl J Med 1981, 305:1590-1591.

49. Pitsavos C, Chrysohoou C, Panagiotakos DB, Skoumas J, Zeimbekis A, Kokkinos P, Stefanadis C, Toutouzas PK: Association of leisure-time physical activity on inflammation markers (C-reactive protein, white cell blood count, serum amyloid $A$, and fibrinogen) in healthy subjects (from the ATTICA study). Am J Cardiol 2003, 91(3):368-370.

50. Church TS, Barlow CE, Earnest CP, Kampert JB, Priest EL, Blair SN: Associations between cardiorespiratory fitness and C-reactive protein in men. Arterioscler Thomb Vasc Biol 2002, 22(11):1869-1876.

51. Morrow J, Nolen-Hoeksema S: Effects of response to depression on the remediation of depressive affect. J Pers Soc Psychol 1990, 58(3):519-527.

52. Nolen-Hoeksema S, Morrow J: A prospective study of depression and posttraumatic stress symptoms after a natural disaster: the 1989 Loma Prieta earthquake. J Pers Soc Psychol 1991, 61(1):115-121.

53. McAuley E, Jerome GJ, Marquez DX, Elavsky S, Blissmer B: Exercise selfefficacy in older adults: social, affective, and behavioral influences. Ann Behav Med 2003, 25(1):1-7.

54. Craft LL: Exercise and clinical depression: examining two psychological mechanisms. Psychol Sport Exerc 2003, 6:151-171.

55. Lewinsohn PM, Gotlib $॥$ : Behavioral theory and treatment of depression In Handbook of depression. 2nd edition. Edited by Beckham EE, Leber WR. New York: Guildford Press; 1995:352-375.

56. Bartoholomew JB, Ciccolo JT: Exercise, depression, and cognition. In Exercise and its mediating effects on cognition, Volume 2. Edited by Spirduso WW, Poon LW, Chodzko-Zajko W. Champaign, IL: Human Kinetcs; 2008.

57. Tselebis A, Moussas G, Bratis D: Psychological intervention in a COPD rehabilitation programme [in Modern Greek]. Pneumonologika Themata 2006:21-23.

58. Lacasse Y, Maltais F, Goldstein RS: Pulmonary rehabilitation: an integral part of the long-term management of COPD. Swiss Med Wkly 2004, 134(41-42):601-605.

59. Paz-Diaz H, Montes de Oca M, Lopez JM, Celli BR: Pulmonary rehabilitation improves depression, anxiety, dyspnea and health status in patients with COPD. Am J Phys Med Rehabil 2006, 86(1):30-36.

60. Pantou I, Harikiopoulou M, Bratis D, et al: The impact of rehabilitationinduced symptomatic, functional and psychological outcomes on healthrelated quality of life, European Respiratory Society, Annual Congress. ; 2006.

61. Coventry PA, Bower P, Keyworth C, Kenning C, Knopp J, Garrett C, Hind D, Malpass A, Dickens C: The effect of complex interventions on depression and anxiety in chronic obstructive pulmonary disease: systematic review and meta-analysis. PLoS One 2013, 8(4):e60532.

62. White RJ, Rudkin ST, Ashley J, Stevens VA, Burrows S, Pounsford JC, Cratchley G, Ambler NR: Outpatient pulmonary rehabilitation in severe chronic obstructive pulmonary disease. J R Coll Physicians Lond 1997, 31:541-545.

63. Pantou I, Harikiopoulou M, Mpletsa M, et al: Does the severity of chronic obstructive pulmonary disease reflect on the outcomes of pulmonary rehabilitation? European Respiratory Society, Annual Congress. 2007.

64. Trappenburg JC, Troosters T, Spruit MA, Vandebrouck N, Decramer M, Gosselink R: Psychosocial conditions do not affect short-term outcome of multidisciplinary rehabilitation in chronic obstructive pulmonary disease. Arch Phys Med Rehabil 2005, 86(9):1788-1792.

65. Edmunds M, Scudder L: Examining the Relationships Between COPD and Anxiety and Depression. Heart Lung 2009, 38:34-47.

66. Kunik ME, Roundy K, Veazey C, Souchek J, Richardson P, Wray NP, Stanley MA: Surprisingly high prevalence of anxiety and depression in chronic breathing disorders. Chest 2005, 127:1205-1211. 
67. Hill K, Geist R, Goldstein RS: Anxiety and depression in end-stage COPD. Eur Respir J 2008, 31(3):667-677.

68. Tselebis A, Kosmas E, Bratis D, Moussas G, Karkanias A, llias I, Siafakas N, Vgontzas A, Tzanakis N: Prevalence of alexithymia and its association with anxiety and depression in a sample of Greek chronic obstructive pulmonary disease (COPD) outpatients. Ann Gen Psychiatry 2010, 9:16.

69. Papaioannou Al, Loukides S, Gourgoulianis Kl, Kostikas K: Global assessment of the COPD patient: Time to look beyond FEV1? Respir Med 2009, 103:650-660.

doi:10.1186/2049-6958-8-41

Cite this article as: Tselebis et al.: A pulmonary rehabilitation program reduces levels of anxiety and depression in COPD patients.

Multidisciplinary Respiratory Medicine 2013 8:41.

\section{Submit your next manuscript to BioMed Central and take full advantage of:}

- Convenient online submission

- Thorough peer review

- No space constraints or color figure charges

- Immediate publication on acceptance

- Inclusion in PubMed, CAS, Scopus and Google Scholar

- Research which is freely available for redistribution 